Western University

Scholarship@Western

Aboriginal Policy Research Consortium International (APRCi)

2007

\title{
Learning From the Grandmothers: Incorporating Indigenous Principles Into Qualitative Research
}

Charlotte Loppie

Follow this and additional works at: https://ir.lib.uwo.ca/aprci

Part of the Community-Based Research Commons, and the Health Services Research Commons

Citation of this paper:

Loppie, Charlotte, "Learning From the Grandmothers: Incorporating Indigenous Principles Into Qualitative Research" (2007). Aboriginal Policy Research Consortium International (APRCi). 275.

https://ir.lib.uwo.ca/aprci/275 


\title{
Qualitative Health Research
}

http://qhr.sagepub.com/

\section{Learning From the Grandmothers: Incorporating Indigenous Principles Into Qualitative Research Charlotte Loppie \\ Qual Health Res 2007 17: 276 \\ DOI: $10.1177 / 1049732306297905$}

The online version of this article can be found at:

http://qhr.sagepub.com/content/17/2/276

\author{
Published by: \\ (S)SAGE \\ http://www.sagepublications.com \\ Additional services and information for Qualitative Health Research can be found at: \\ Email Alerts: http://qhr.sagepub.com/cgi/alerts \\ Subscriptions: http://qhr.sagepub.com/subscriptions \\ Reprints: http://www.sagepub.com/journalsReprints.nav \\ Permissions: http://www.sagepub.com/journalsPermissions.nav \\ Citations: http://qhr.sagepub.com/content/17/2/276.refs.html \\ >> Version of Record - Jan 12, 2007 \\ What is This?
}




\title{
Learning From the Grandmothers: Incorporating Indigenous Principles Into Qualitative Research
}

\author{
Charlotte Loppie \\ Dalhousie University, Halifax, Nova Scotia, Canada
}

\begin{abstract}
In this article, the author describes the process she undertook to incorporate Indigenous principles into her doctoral research about the midlife health experiences of elder Aboriginal women in Nova Scotia, Canada. By employing qualitative methods within the context of an Indigenous worldview, she gained knowledge of and developed competence in Aboriginal health research. The emergent partnership among Aboriginal community research facilitators, participating Mi'kmaq women, and the researcher provided many opportunities for the researcher to incorporate the paradigmatic and methodological traditions of Western science and Indigenous cultures. The application of these principles to this study might provide a useful example for other health researchers who are attempting to incorporate diverse methodological principles.
\end{abstract}

Keywords: First Nations; Aboriginal peoples; North American Indians; qualitative research

$\mathrm{I}_{\mathrm{c}}^{\mathrm{n}}$ this article, I describe the process I undertook to conduct my doctoral research with $\mathrm{Mi}^{\prime} \mathrm{kmaq}^{1}$ women, emphasizing the ways in which I attempted to incorporate Western scientific and Indigenous principles into the research process. The purpose of the study on which this article is based was to explore the perceptions (physical, psychological, emotional, social, and spiritual) of midlife health, with particular emphasis on the menopausal transition, among midlife Mi'kmaq women in Nova Scotia.

That study built on master's thesis research (Loppie, 1997) concerning the knowledge, attitudes, and experiences of menopause among African Canadian, Aboriginal, ${ }^{2}$ and Euro-Canadian women. The findings of that study highlighted the distinct influence of cultural contexts on women's conceptualization and experience of menopause, which supported previous research (Berger, 1999; Beyenne, 1989; Lock, 1993). Moreover, the Mi'kmaq women who participated in that study expressed a concern about the lack of information relevant to Aboriginal women's midlife experiences and the consequent difficulties they encountered due to lack of knowledge or misinformation. Finally, throughout that inquiry, I became aware of the tension in conducting Western social science research among Aboriginal peoples, as well as my own ignorance about how to negotiate a more equitable process. By detailing the ways in which I applied Indigenous principles to my research, I hope to provide useful insights and applications for others who wish to undertake Aboriginal health research.

\section{Cultural Themes of Indigenous Peoples}

The most noteworthy preface to any discussion of Indigenous ${ }^{3}$ peoples is that a universal Indigenous paradigm does not exist. Despite diversity of geography, language, and social structure, however, Indigenous peoples do share many values that are philosophically distinct from Euro-American and Euro-Canadian cultural imperatives.

Since time immemorial, Indigenous cultures and histories were passed from generation to generation through an oral tradition. Storytelling or narrative was used extensively as a teaching tool. Within many Indigenous cultures, narrative symbolizes holism, in the sense that stories function to connect that which is central to individual, community, and social processes (Cruikshank, 1990). Through stories, myths, and legends, elders symbolically describe socially appropriate behavior and share knowledge, philosophy, and instruction without direct censorship (Battiste, 2000; Brant, 1990). Another unique and enduring characteristic of 
Indigenous stories is that they are dynamic, in the sense that they evolve over time in much the same way that people and cultures do. Stories are also contextual and can be tailored to fit the circumstances under which they are told, as well as being process oriented, so they can guide decision making and problem resolution (Leavitt, 1995; Waldram, Herring, \& Young, 1995).

Indigenous societies have always possessed sophisticated systems of knowledge, philosophy, medicine, and government (Battiste, 2000; Gunn-Allen, 1986; Smith, 2000). A gestalt paradigm is often reflected in value themes of holism, which emphasizes the complete person in the entirety of his or her life; personalism, which places value on individual autonomy and freedom; relationality, which acknowledges responsibility toward self, community, environment, and cosmos; and balance and harmony, which acknowledge the sacredness of existence as well as unconditional reverence and respect for humans and nonhumans alike (Gunn-Allen, 1986; Klein \& Ackerman, 1995; McMillan, 1995).

\section{Paradigmatic Perspectives}

Western constructivist and Indigenous paradigms generally agree that reality is a product of multiple human constructions, woven from the fibers of individual and collective context, perception, and action. Each construction evolves over time and exists for as long as it is useful or until a new construction takes its place as a more reliable or relevant representation of reality. Reality is transformative and transactional. More simply put, each interaction represents a new negotiation, which creates the context, text, and subtext of human understanding, which is thus experienced within existential and embodied domains (Battiste, 2002; Castellano, 2000; Guba \& Lincoln, 1994).

In this study, I was challenged to present multiple constructions that define and refine reality from the perspectives of Aboriginal research partners and me. This process involved careful consideration and sharing of my discoveries in an effort to express diverse constructions that were relevant and useful to academics as well as to Aboriginal community partners. The most notable element of my evolving perspective has been the specific contribution made by the Aboriginal women who partnered in this research. During the process of talking and listening to them, as well as reading and thinking about Indigenous ways of knowing, I have come to understand that beyond acknowledging the social construction of reality, we must also accept its plurality. Indigenous principles further instruct me to recognize the fluidity of human constructions and to consider the entirety of human reality in relation to the minutiae of human existence and lived experience (Castellano, 2000).

\section{Method}

\section{Research Design}

The emergent nature of both Indigenous knowledge (Castellano, 2000) and qualitative inquiry (Guba \& Lincoln, 1989) necessitated the development of a research design that accommodated the multiple realities and unpredictable interactions between research partners. The flexibility of my design was evident in its emergence through collaboration and consensus building with participating communities and participants. The overall design represented an amalgamation of the principles of Indigenous and Western methodological traditions (i.e., ethnography, participatory research, and feminism).

\section{Indigenous Principles}

In designing this study, I positioned myself within a prevalent Indigenous epistemology by acknowledging the wisdom of elder women and inviting their partnership in storytelling as a vehicle of teaching, learning, and sharing (Battiste, 2002; Castellano, 2000). Not surprisingly, the participants of this study favored group discussions as a means of sharing their experiences and engaging in reciprocal learning and healing. My learning also came from listening to, observing, and interacting with the women who partnered in this research and not necessarily from the literature that had previously shaped my perspective, nor from Eurocentric methods that assume the inferiority of experiential pedagogy (Henderson, 2000; Posey, 2004; Smith, 2000).

Many Indigenous principles foreground the interconnectedness of that which Western science often seeks to separate. For example, rather than a linear process, whereby each discrete step of the research process is followed by another discrete step, Indigenous methods generally emphasize the ways in which interrelated constituents flow together to facilitate the goals of the research, the relationship between research partners, and the potential service of the research process and products (Henderson, 2000; 
Smith, 2005). In this case, the decision to use group discussions to gather data emerged from the opportunities afforded by this method to engage in reciprocal learning and sharing of stories. Similarly, the engagement of intuition in the analysis process arose from the grandmothers' accentuation of holistic learning, which involves all of the senses, not just those related to cognition. Submission of this article for academic publication represents its potential to act as a conduit through which other researchers may learn from this process and conduct future research that is respectful of and beneficial to Aboriginal peoples.

\section{Ethnographic Principles}

The practice of culture, a uniquely human construction, endows the world of cultural participants with symbolic meaning. According to Berg (1995), ethnography is the work of describing culture. However, it has been conceptualized in various ways by a number of experts, often including "the study and analysis of Indigenous peoples' viewpoints, beliefs and practices . . behaviours and processes" (Leinger, 1985, in Berg, 1995, p. 38). In this study, an ethnographic approach contextualized and emphasized the social and cultural meaning of Aboriginal women's experiences. Ethnographic methods involve talking to people about how they experience the world, how they understand and organize their behavior, and how they go about living their lives (Berg, 1995).

Many aspects of this research fit within a general ethnographic framework because the design involved components essential to understanding midlife health and the perimenopausal transition from an Indigenous perspective. It also placed me in the midst of those with and from whom I gathered information (Berg, 1995). This research fit best within the framework of microethnography, in that it focused on a particular and salient element in the lives of a distinctive group of women (Berg, 1995). The subsequent findings were descriptive in terms of the "real" world of midlife Aboriginal women, as well as analytic in the sense that I offered a potential extrapolation of beliefs, attitudes, and experiences that might be shared by other Aboriginal women. These suggestions were based on current, albeit limited, written information about the historical traditions of Indigenous peoples.

The research design's embrace of ethnographic principles assisted me in emphasizing distinct perspectives and contexts that form the foundation of Aboriginal women's experience (Patton, 1990). This enhanced cultural understanding emerged from sustained contact with women in diverse Aboriginal communities. In addition to repeated meetings with women who agreed to act as community facilitators, I facilitated each group discussion and socialized with participants before and after groups. During the course of this study, I also established relationships with many of the community facilitators and participants, the outcome of which is my continued collaboration on community projects.

\section{Participatory Practice}

Participatory research is intimately linked to many Indigenous philosophies through the value of local participation, learning through action, collective decision making, and empowerment through group activity. This philosophy also embraces the participation of diverse senses and capacities, including the physical, emotional, psychological, spiritual, and social. The products of participatory research also promote selfdetermination of Aboriginal peoples by enhancing self-reliance, consciousness, and the creation of useful information (Jackson, 1993).

Since 1969, participatory research has been conducted under the auspices of the Aboriginal people's movements in general and by several submovements in particular (e.g., status and nonstatus Indians, Métis, Inuit, Aboriginal women, and urban Natives). Nevertheless, participatory research has yet to be fully used in the area of Aboriginal health (Dickason, 2000; Jackson, 1993; National Aboriginal Health Organization, 2002). In fact, until very recently, Aboriginal people were seldom invited to participate in health research beyond their role as data sources (Dickason, 2000).

Through the engagement of participatory principles, the community partners and I designed this study to reflect a deep respect for the intellectual and intuitive capacities of Aboriginal women. Full and active participation by Aboriginal women in the development of the research project, recruitment of participants, and modification of the discussion guide, as well as collection and analysis of data, ensured a participatory approach of mutual benefit. Indeed, through this collaborative mode of research, I attempted to honor our diverse knowledge and expertise, as well as "distribute power more equitably among the various" research partners, thereby creating harmony within the group (Glesne \& Peshkin, 1991, p. 100). Nevertheless, each woman was free to choose the extent to which she participated in various components of the project. For instance, some chose to sit in on discussion groups, whereas others engaged more fully in reflecting on and interpreting the data. 


\section{Feminist Principles}

The most basic tenets of feminism seek to explore and influence social, economic, and political oppression and agency relative to women (Berger, 1999; Dickson, 1990). In health research, nowhere has resistance to the practice and consequences of genderbased, biological determinism been more evident than in feminist research concerning women's health over the life cycle, which has inspired a number of qualitative studies concerning women's perceptions and experiences of menopause (Berger, 1999; Beyene, 1989; Davis, 1983). Unfortunately, however, most studies have remained rather narrowly focused on issues most salient to White women of the middle class. This assumption of a homogeneous menopausal experience ignores the diversity of women's everyday circumstances and the influence of social determinants (Burger \& Boulet, 1991; Hardy \& Kuh, 2005; Stotland, 2002). In particular, studies that do not account for women's ethnoracial background, socioeconomic status, existing health status, life circumstances, or cultural context fall short of contributing meaningful information about their menopausal experience (Bell, 1987; Berger, 1999).

In this research design, I incorporated feminist traditions within the context of Indigenous principles of holism by focusing on the entirety of women's realities (Lather, 1991). I emphasized relationality by rejecting the separation of subject and object. Rather, data collection represented an equal, two-way exchange of information. I promoted balance and harmony by continuously and reflexively considering the significance of culture and gender as well as attending to ethical concerns related to respectful and reciprocal research with Aboriginal people. Finally, I emphasized personalism and the empowerment of women by integrating participation and consciousness raising into the research process (Bowles \& DuelliKlein, 1983; Cook \& Fonow, 1991; Kirby \& McKenna, 1989).

\section{Ethical and OCAP Considerations}

In 2000, the National Aboriginal Health Organization established a set of ethical principles, referred to as OCAP (ownership, control, access, and possession) that would shape research conducted with Aboriginal peoples in Canada (Schnarch, 2004). Since then, the TriCouncil funding agencies of Canada have led academic institutions throughout the country to implement similar principles in their research ethics guidelines (Canadian Institutes of Health Research, 2005).
In developing and implementing this study, I demonstrated my respect for OCAP principles by engaging in meaningful partnership with participating women and their communities. In particular and where applicable and desired, I offered to formalize this relationship through a partnership agreement that outlined the conditions under which the communities agreed to partner in the research, in terms of the OCAP principles. Support from the Mi'kmaq Health Research Group, ${ }^{4}$ The Mi'kmaq Ethics Watch, ${ }^{5}$ First Nations Health Directors, ${ }^{6}$ and participating women confirmed my intention that participation in this study would benefit the Mi'kmaq people and would not pose inordinate risk to participants or their communities. In fact, I made every effort to ensure that participants were not inconvenienced or offended by the methods used to gather this information. Most important, I have ensured that the presentation of the findings was respectful of Aboriginal peoples, their beliefs, and their traditions by obtaining consensus from community partners and participants on the analysis framework, interpretation, and dissemination of the research findings.

\section{Making the Community Connection}

My research relationship with various Aboriginal communities began in 1997, when I invited women of diverse ethnocultural backgrounds to participate in my master's thesis research. Through my continued involvement with members of the Mi'kmaq Nation, I have developed greater rapport with Aboriginal women, in the sense that our "relation [is] characterized by harmony, conformity, accord, [and] affinity" (Mish, 1989, p. 1882). However, I continue to receive instruction from the grandmothers regarding distinctive cultural norms and behaviors, so that I can enhance my cultural competence for current and future interactions with research partners.

I began to build partnerships for my doctoral research by seeking the support and endorsement of First Nation communities in Nova Scotia, then networking within each community and engaging community facilitators. Despite my Euro-Aboriginal ancestry, it was also essential that I become familiar with specific cultural values and norms, as well as culturally appropriate approaches to research with the Mi'kmaq people (Berg, 1995). It was particularly important to understand potential barriers to participation, including language, which related not just to linguistics but also to cultural meaning. Similarly, through adherence to the principles of OCAP, I attempted to address issues related to confidentiality, 
distrust of researchers and the research process, and skepticism about the value for the community of participation. I also acknowledge that the recent flood of research in Aboriginal communities, which competes with Aboriginal women's multiple responsibilities, might have influenced individuals' willingness to participate in the research process (Berg, 1995).

After preliminary consultation with the Mi'kmaq Health Research Group and approval by the Mi'kmaq Ethics Watch, my initial contact was with health directors or community health representatives (CHR) in selected communities. If required, I also requested approval to conduct the research from the band manager (a term used by the Mi'kmaq Nation) or chief and council. During my initial meetings with these key informants, I invited the participation of community women to partner in the research, and we discussed (a) the purpose of the study, (b) the risks and benefits to participating research partners, (c) strategies for collecting data and ensuring confidentiality, (d) payment of honoraria, (e) potential audiences, (f) application of the findings (e.g., future research, Aboriginal health care policy, programs, and practice), (g) development of the interview guide, and (h) community protocols.

\section{Participant Selection and Invitation}

In this study, we (i.e., community members who agreed to partner in the study and I) included six groups, totaling $42 \mathrm{Mi}$ ' $\mathrm{kmaq}$ women ranging from 38 to 83 years of age, from five First Nation communities in Nova Scotia. A number of techniques, including purposive, snowball, and opportunistic sampling, were employed (Patton, 1990). Facilitators from each participating community were asked to contact five or six women and invite them to participate in a group discussion about midlife health and menopause.

During these initial discussions, facilitators provided women with information about the purpose of the study; the process of data collection (audiotaped groups); the responsibilities, risks or inconveniences, and benefits of participation; assurances of confidentiality; and any additional information potential participants required or requested. Each participant also received an information letter describing the study in plain language. Local community centers and health centers were chosen as the most convenient places to conduct the groups; community facilitators and participants negotiated the dates and times. This sharing of decision-making power as well as open communication were critical components of this participatory research process (Kirby \& McKenna, 1989).

\section{Forming the Circle}

Before each discussion, participants were asked to verify that they understood what the study was about. They were also asked to give their consent to participate in the group discussion and to be audiotaped. Each group was also given the option of having me, the community facilitator, or both of us ask the questions that would guide our discussion. All of the groups chose to have me ask the main questions and have both the facilitator and me follow up with probes.

For women whose first language is Mi'kmaq, I offered to have the facilitator or another woman act as an interpreter. However, all of the women indicated a willingness to carry out the groups in English. In an effort to respect various levels of literacy, I also reviewed the introduction letter and the consent form aloud. Participants were given the option of providing either written or oral consent. Finally, for those women who might not feel comfortable discussing menopause in a group setting, I offered the opportunity to participate in a one-on-one interview. However, all of the women indicated that they felt comfortable participating in the group discussion.

In addition to obtaining ethical approval from all of the relevant stakeholders, the process of community engagement took approximately 18 months. A number of factors contributed to this, including the fiscal yearend activities of First Nation communities (February and March) as well as summer vacations (July and August). Perhaps the most critical issue was my status as an unknown in the many of the communities. Despite my genetic connection to the Mi'kmaq people, I have no documented Aboriginal status, and neither my family nor I were raised on a reserve. The added hindrance of my position as a university researcher created a barrier to trust that only time and respectful persistence could overcome. Some communities were more receptive than others, and these were the first to participate. Yet, my work with the Mi'kmaq Health Research Group and with various community projects enhanced my familiarity with communities and them with me, thus fostering trust and rapport.

Social activities were incorporated into every group meeting. This cultural custom of including opportunities to socialize provided an opportunity for me to get to know the women and for them to become more comfortable with me. During pregroup visits, I 
told the women about me, who I am, where I am from, and why I was doing the project.

My first group began with a lunch, and some women also remained after the discussion to ask questions about menopause and other health issues. My second group began with snacks and a visit, which also extended beyond the group discussion. The third and fourth groups were held at a community center on the same day and were separated by a tea/lunch. The fifth group lasted most of the day, because a menopause workshop and a supper followed the group. The final group began with a light snack and social; at most gatherings, the women invited me to return for community workshops on menopause as soon as I could.

By and large, the women were very enthusiastic about having the opportunity to share their experiences and to learn more about midlife change. Our talks were relaxed and lighthearted; the women laughed a lot and made me feel very welcomed, and most want me to continue to develop a project that would share this information with other Aboriginal women, particularly youth.

\section{Gathering Grandmothers ${ }^{97}$ Stories}

The process of the groups seemed to encourage discussion of sensitive subjects, as members might have felt less inhibited because others were willing to talk as well as convey mutual support and qualify their perspectives. Within most Indigenous paradigms, knowledge is shared through stories that are intended to teach. Women shared stories of their family and community as well as their life experiences and history. In particular, sharing past experiences was particularly important, as it created an environment of safety and support (Wadsworth, 2000). The sharing of experiences was also informative for many of the women involved, not only in terms of information about menopause but also in gauging their experience against that of other women. Listening to the stories of other women also triggered memories and responses or helped women to recall their own experiences (Wadsworth, 2000). One elder woman claimed that she had learned more about her body in that single afternoon of talking to other women and me than she had learned in her 83 years.

These benefits of group discussion are somewhat universal; however, the dynamics of a discussion group of First Nations women, particularly older women, many of whom were raised with the traditional values and practices of the Mi'kmaq people, might differ substantially from those involving other groups of women. In general, First Nations people are very respectful of others' opinions (Wadsworth, 2000), so these women did not query one another during discussions, making conflict within the context of group discussions rare. Some researchers might view this practice as a potential limitation of group discussions. However, many Aboriginal peoples simply express their perceptions through other, more diplomatic means (Brant, 1990). In these groups, a simple yet poignant story or well-placed comment later in the discussion clearly conveyed a contrary opinion without overtly disrespecting another's point of view.

\section{Reflecting on My Journey}

After each meeting, I debriefed with the community facilitator and received feedback about the process and content of our group discussion. Although the initial feedback was overwhelmingly positive, I invited facilitators to forward me any additional comments or concerns at any time throughout the study. This feedback has also been encouraging. In fact, one group was so successful that word spread to another community, in which the women approached the Health Director, requesting that I be invited to conduct a group with them.

I documented this journey I undertook with Mi'kmaq women in two journals, in which I recorded my public and private reflections. Throughout the research process, I kept a methodological journal that chronicled such things as materials, time, and location of groups, as well as physical space required. It also includes working models, notes about potential avenues of discovery (e.g., data sources, questions, literature), and possible early links within the data (Patton, 1990). In a private journal, I recorded my reflective impressions, reactions, and interpretations. These notes include my feelings about my relationship with various research partners, my intuition about the meaning of particular conversations, comments about the quality of group discussions, responses and observations, my reactions to others' remarks or behavior, and speculation about the meaning of events or interactions (Miles \& Huberman, 1994). I was astonished at the degree to which this "academic activity" has affected me on a personal level; this is not a component of research often discussed in doctoral methodology courses. Suffice to say that I departed this project having been dramatically changed by it. 


\section{Learning My Lessons}

One of the subtle lessons offered to me by the grandmothers was that any learning I gleaned from this inquiry should come from a deeply personal place. Although I was obligated to share findings in a meaningful way with a myriad of audiences, particularly Aboriginal peoples, I was also tasked with coming to "know" the women's realities from my unique perspective. Unfortunately, within Western science, most of graduate students' learning about qualitative analysis tends to focus on the fragmented process of conceptual distillation and thematic expansion. Indigenous methods emphasize a more holistic process, which combines intuition, dreams, memories, and tacit learning that extend beyond the boundaries of cognition (Battiste, 2000; Brant Castellano, Davis, \& Lahach, 2001; Henderson, 2000).

In an attempt to honor Western methods, during my initial analysis, I followed a modified grounded theory approach (open, axial, and selective coding), in which I derived themes inductively and deductively (Patton, 1990). This process of discovering concepts most relevant to describing and explaining this phenomenon occurred through an intimate examination of the data. In addition to identifying core categories and contexts, this process represented the initial stage of discerning and verifying the theoretical framework emerging from those constituents.

A summary of my initial analysis was sent to community partners for review and discussion. When we were comfortable with how the data were fitting together, I began to delve into the major themes, to discover the deeper meaning of women's words. This process was both intellectual and intuitive, and was based on my relationship with the women, my knowledge of women's health and menopause, and my understanding of Indigenous philosophies, First Nations history, and Mi'kmaq culture. This process was also emotionally, psychologically, and spiritually laborious, because it required the prolonged and intimate engagement of my consciousness regarding the challenges continuing to face Aboriginal women. According to Indigenous scholars (Battiste, 2002; Brant Castellano et al., 2001; Smith, 2000), this engagement of multiple capacities is crucial to learning, particularly with respect to the historical and sociopolitical context of Aboriginal women's lives.

The most obvious tension in research that attempts to conflate Western and Indigenous approaches of inquiry begins with paradigmatic, ontological, and epistemological differences, which have been discussed extensively by other authors (Battiste, 2000; McIsaac, 2000; Royal Commission on Aboriginal Peoples, 1996; Simpson, 2000). Through this research, I have learned that researchers conducting inquiries that incorporate Indigenous and Western principles should also consider challenges related to method, skill, and creativity. The process of adequately documenting Western research methods is a staple of most graduate instruction. Incorporating those methods into the context of Indigenous principles requires humility, commitment, and connection. The process is prolonged and should engage research partners intellectually, socially, and emotionally. Within this context, skill development is an iterative process, whereby junior researchers must likewise fully engage in inquiry, seek out and accept the council and instruction of others (academic and Aboriginal), and apply their learning to successive iterations. Accepting our failure to always "get it right" or that the concept of "right" does not necessarily exist within many paradigms is often difficult for Western researchers.

Creativity is perhaps the most challenging constituent of Indigenous/Western research. Although creative expression is an essential component of Indigenous knowledge, (Battiste, 2002; Brant Castellano et al., 2001), this creativity is often constrained by disciplinary boundaries and notions of acceptability within scientific literature. Thus, we must often conceptualize, plan, develop, and implement research on a tightrope that many do not successfully traverse. I hope that through this article, I have offered some useful insights into and examples of how to apply Indigenous and Western principles in a qualitative research project. This information might have utility for others wishing to undertake respectful, collaborative health research with Aboriginal peoples.

\section{Notes}

1. The Mi'kmaq are one of the Indigenous peoples of eastern Canada. The traditional territory of the Mi'kmaq people includes Nova Scotia, eastern New Brunswick, Prince Edward Island, Newfoundland, and parts of Quebec (Prins, 1996).

2. The term Aboriginal refers to First Nations (formerly referred to as Indians), Inuit (formerly referred to as Eskimos), and Métis peoples of Canada. (Statistics Canada, 1993).

3. Indigenous peoples are defined as "those who have a historical continuity with the pre-invasion and pre-colonial societies that developed on their territories" (Summit on Indigenous Peoples, 2003, para. 1).

4. The Mi'kmaq Health Research Group (MHRG) represents a collaboration of members of the Confederacy of Mainland 
Mi'kmaq, the Union of Nova Scotia Indians, and the Atlantic Policy Congress of First Nation Chiefs, as well as Aboriginal and non-Aboriginal faculty members from Dalhousie University. The goal of the MHRG is to improve educational opportunities and strengthen the research base relevant to the health concerns of the Mi'kmaq communities in Nova Scotia.

5. "The Mi'kmawey L'nui Skmaqn, or Mi'kmaw Ethics Watch, was established to review proposals for research conducted among and with Mi'kmaw people using the Mi'kmaw Principles and Guidelines for the Protection of Mi'kmaw Heritage and People. These principles and protocols include the expectation that researchers will follow the highest standards of research with sensitivity and respect to protocols appropriate to Mi'kmaw people and their communities" (Mi'kmaq Ethics Watch, 1999, p. 1).

6. Health directors are employees of individual First Nations who are responsible for coordinating primary health care services and programs on the reserve.

7. Grandmother is a term used by many Indigenous cultures, in the context of their unique communities, to address older women in a respectful manner. Within many of these Indigenous traditions, younger people listen carefully to senior women, taking their advice seriously and looking to them as role models (Dickason, 2000).

\section{References}

Battiste, M. (2000). Reclaiming indigenous voice and vision. Vancouver, Canada: UBC Press.

Battiste, M. (2002). Indigenous knowledge and pedagogy in First Nations education: A literature review with recommendations. Ottawa, Canada: National Working Group on Education and the Minister of Indian Affairs, Indian and Northern Affairs Canada.

Bell, S. (1987). Changing ideas: The medicalization of menopause. Social Science and Medicine, 24, 535-542.

Berg, B. (1995). Qualitative research methods for the social sciences (2nd ed.). Toronto, Canada: Allyn and Bacon.

Berger, G. (1999). Menopause and culture. London: Pluto.

Beyene, Y. (1989). From menarche to menopause: Reproductive lives of peasant women in two cultures. Albany: State University of New York Press.

Bowles, G., \& DuelliKlein, R. (Eds.). (1983). Theories of women's studies. New York: Routledge Kegan Paul.

Brant, C. (1990). Native ethics and rules of behaviour. Canadian Journal of Psychiatry, 35, 534-539.

Brant Castellano, M., Davis, L., \& Lahach, L. (2001). Aboriginal education: Fulfilling the promise. Victoria, Canada: University of British Columbia Press.

Burger, H., \& Boulet, M. (Eds.). (1991). A portrait of the menopause: Expert reports on medical and therapeutic strategies for the 1990s. Park Ridge, NJ: Parthenon.

Canadian Institutes of Health Research. (2005). CIHR guidelines for health research involving Aboriginal peoples. Ottawa, Canada: Author.

Castellano, M. (2000). Updating Aboriginal traditions of knowledge In G. Dei, B. Hall, \& D. Rosenberg (Eds.) Indigenous knowledges in global contexts (pp. 21-36). Ontario, Canada: University of Toronto Press.
Cook, J., \& Fonow, M. (1991). Beyond methodology: Feminist scholarship as lived research. Bloomington: Indiana University Press.

Cruikshank, J. (1990). Life lived like a story: Life stories of three Yukon Native elders. London: University of Nebraska Press.

Davis, D. (1983). Blood and nerves: An ethnographic focus on menopause. St. John's, Canada: Institute of Social and Economic Research, Memorial University, Newfoundland.

Dickason, O. (2000). Aboriginal grandmothers' experience with health promotion and participatory action research. Qualitative Health Research, 10, 188-213.

Dickson, G. (1990). A feminist post-structuralist analysis of the knowledge of menopause. Advances in Nursing Science, 12, 15-31.

Glesne, C., \& Peshkin, A. (1991). Become qualitative researchers: An introduction. New York: Routledge.

Guba, G., \& Lincoln, Y. (1989). Forth generation evaluation. London: Sage.

Guba, E., \& Lincoln, Y. (1994). Competing paradigms in qualitative research. In N. Denzin \& Y. Lincoln (Eds.), Handbook of qualitative research (pp. 105-117). Thousand Oaks, CA: Sage.

Gunn Allen, P. (1986). The sacred hoop: Recovering the feminine in American Indian traditions. Boston: Beacon.

Hardy, R., \& Kuh, D. (2005). Social and environmental conditions across the life course and age at menopause in a British birth cohort study. British Journal of Obstetrics and Gynecology, 112(3), 346-354.

Henderson, J. (2000). Ayukpachi: Empowering Aboriginal thought. In M. Battiste (Ed.). Reclaiming indigenous voice and vision (pp. 248-278). Vancouver, Canada: UBC Press.

Jackson, T. (1993). A way of working: Participatory research and the Aboriginal movement in Canada. In P. Park, M. BrydonMiller, B. Hall, \& T. Jackson (Eds.), Voices of change: Participatory research in the United States and Canada (pp. 47-64). Toronto, Canada: OISE.

Kirby, S., \& McKenna, K. (1989). Experience research social change: Methods from the margins. Toronto, Canada: Garamond.

Klein, L., \& Ackerman, L. (Eds.). (1995). Women and power in Native North America. London: University of Oklahoma Press.

Lather, P. (1991). Getting smart: Feminist research and pedagogy with/in the postmodern. New York: Routledge.

Leavitt, R. (1995). Malliseet and Micmac: First Nations of the Maritimes. Fredericton, Canada: New Ireland.

Lock, M. (1993). Encounters with aging: Mythologies of menopause in Japan and North America. London: University of California Press.

Loppie, C. (1997). The climacterium: Women's attitudes, sources of information and experiences. Unpublished master's thesis, Dalhousie University, Halifax, Canada.

McIsaac, E. (2000). Oral narratives as a site of resistance: Indigenous knowledge, colonialism, and western discourse. In G. J. Dei, B. L. Hall, \& D. G. Rosenberg (Eds.), Indigenous knowledges in global contexts (pp. 89-101). Toronto, Canada: University of Toronto Press.

McMillan, A. (1995). Native peoples and cultures of Canada: An anthropological overview (2nd ed.). Toronto, Canada: Douglas \& McIntyre. 
Mi'kmaq Ethics Watch. (1999). Mi'kmaq research principles and protocols. Chapel Island, Nova Scotia: Author.

Miles, M., \& Huberman, A. (1994). Qualitative data analysis: An expanded sourcebook (2nd ed.). Thousand Oaks, CA: Sage.

Mish, F. (Ed.). (1989). The new Merriam-Webster dictionary. Springfield, MA: Merriam-Webster.

National Aboriginal Health Organization. (2002). Who's doing what: An environmental scan of select provincial, national, and international health-related organizations/initiatives that may influence Aboriginal health policy. Ottawa, Canada: Author.

Patton, M. (1990). Qualitative evaluation and research methods. Beverly Hills, CA: Sage.

Posey, D. (2004). Indigenous knowledge and ethics: A Darrell Posey reader. New York: Routledge.

Prins, H. (1996). The Mi'kmaq: Resistance, accommodation, and cultural survival. Fort Worth, TX: Harcourt Brace.

Royal Commission on Aboriginal Peoples. (1996). Perspectives and realities (Vol. 4). Retrieved April 11, 2006, from http:// www.ainc.inac.bs.ca/ch/rcap/sh/sj1_e.html

Simpson, L. (2000). Indigenous knowledge and Western science: Towards new relationships for change. In J. Oakes, R. Riewe, S Koolage, L. Simpson, \& N. Schuster (Eds.), Aboriginal health, identity and resources. (pp. 186-195). Winnipeg, Canada: Native Studies Press.

Smith, L. T. (2000). Kaupapa Maori research. In M. Battiste (Ed.), Reclaiming indigenous voice and vision (pp. 225-247). Vancouver, Canada: UBC Press.
Smith, L. (2005). Decolonizing methodologies: Research and indigenous peoples. London: Zed.

Schnarch, B. (2004). Ownership, control, access, and possession (OCAP) or self-determination applied to research: A critical analysis of contemporary First Nations research and some options for First Nations communities. Journal of Aboriginal Health, 1(1), 80-95.

Statistics Canada. (1993). Language, tradition, health, lifestyle and social issues: 1991 Aboriginal Peoples Survey (Catalogue No. 89-533). Ottawa, Canada: Queen's Printer.

Stotland, N. (2002). Menopause: Social expectations, women's realities. Archives of Women's Mental Health, 5(1), 5-8.

Summit on Indigenous Peoples. (2003, March). Resolution 1.2: Canadian International Model United Nations Conference. Ottawa, Canada: Assembly of First Nations. Retrieved November 24, 2006, from http://www.canimun.org/english/CANIMUN_ 2003/Resolutions/ind_ENG_1.2.pdf

Wadsworth, G. (2000). Hearing midlife voices: Assessing different methods for researching women's experience of menopause and midlife. Women's Studies International Forum, 23, 645-654.

Waldram, J., Herring, A., \& Young, T. (1995). Aboriginal health in Canada: History, culture and epidemiological perspectives. Toronto, Canada: University of Toronto Press.

Charlotte Loppie, $\mathrm{PhD}$, is an assistant professor in the Faculty of Health Professions at Dalhousie University, Halifax, Nova Scotia, Canada. 